\title{
Online Voting System Using Biometric Verification
}

\author{
Prof. M.N. Annadate ${ }^{1}$, Shreyans Sunil Gandhi ${ }^{2}$, Nivita Ravi Kaniampal ${ }^{3}$, Pushkar Satish Naral ${ }^{4}$ \\ Assistant Professor, Electronics and Telecommunications Engineering, MIT COE, Pune, India ${ }^{1}$ \\ BE Student, Electronics and Telecommunications Engineering, MIT COE, Pune, India 2,3,4
}

\begin{abstract}
This paper describes electoral system which is completely automated, unbiased and online for easing the process of voting, increasing security and reducing the counting time The project is divided mainly into two section first one is voter registration phase of voter and second one is of actual voting phase on voting console. In voter registration phase the database of voter will be saved in repository which specifically contains voter's unique identification number and finger prints information. Project contains biometric device which will verify the identity from the database saved in repository by the communication of Wi-Fi module i.e. esp8266 and if respective voter is identified then authorization will approve to that respective voter at the same time in other section of repository it updates the database of authorized voter to register voter is qualify to vote and to uniqueness, also it will prevent the duplication and falsification of voter ;after getting authority from the repository voting enabling signal will send from VVB by using ZigBee to voting console for enabling voting for that particular voter, when voter votes then that vote will send to repository with the help of esp8266 and the voting console will be reset after the voting of each vote.
\end{abstract}

Keywords: Electronic Voting Machine (EVM), Biometric, Voting System, Voting analysis.

\section{INTRODUCTION}

Voting is very effective way to reveal opinion about a issue or subject from a group of people Based on the promise of greater efficiency, better scalability, faster speed, lower cost, and more convenience, voting is currently shifting from manual paper-based processing to automate electronic-based processing [1]. The term "electronic voting" characteristically depicts to the use of some electronic means in voting and ensure the security, reliability, guarantee and transparency. Now a day the wide range of application of voting include its use in reality student body elections, shareholder meetings, and the passing of legislation in parliament [2]. It may be the most important, influential and widespread use of voting is its use in national elections and speaking of national elections there are 204 countries in the world about them 120+ nations follows democratic or hybrid democratic method so electoral system is the heart of these nation. In India we used the electronic voting machine or EVM which is developed by election commission of India and Bharat Electronics limited i.e. BEL in 1977. It consists of mainly two units they are controlling unit and ballot unit, ballot unit is used for the actual voting.

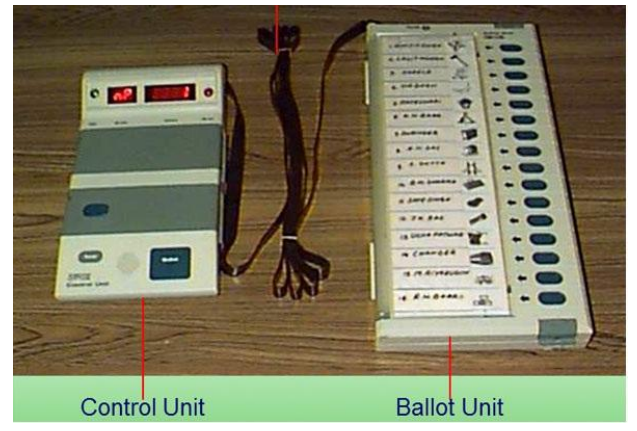

Fig. 1 Hardware of system

The controlling unit is for counting number of votes both units are connected together with a 5-meter-long wire and the maximum no of votes that can be enrol in ballot unit are 3850 but there are some problems associate with this system they are noted below.

\section{A. Security Problems:}

In present day scenario, EVM results can be tampered by manipulating the program stored in the EVM and by installing a look alike component which can be instructed to tamper the results. 


\section{B. Illegal Voting (Rigging) :}

Rigging is a common malpractice in the voting process where supporters of a particular party illegally manage to cast votes of genuine voters and deprive them of their voting rights in order to get the results in their favour.

\section{Privacy}

The anonymity of the voter is preserved and there is no way to link the voter to the vote casted by the voter.

\section{Verifiability}

The system provides means to recheck the results in case there is a necessity to recheck the election results.

\section{E. Availability}

The system ensures full availability to the voters on the polling day .

\section{F. Resume Ability}

Security can be considered the heart of any nations voting system so while developing the system in this project security is given highest priority. Biometric verification is considered as the authentication measure of voter because biometric signature viz. finger print, retina etc. of any person have unique value and these biometric signature of person does not change even after death of person so now a days biometric is giving very effective results which will lead to the illegal voting / rigging of voting. the database of voters and the vote of the voters are going to store into a server which will communicate to all voting booth so there will be flexible of voter to enrol their vote on voting booth which is feasible for voter and due to votes are stored into the server there will no tampering of votes while counting [3].

\section{LITERATURE SURVEY}

During the course of this project development we have referred various papers to analyse the problems in the existing system and figure out solutions that are economically viable. Background research on the organization and comparative studies of existing systems is also done to more understand the system requirements before the system was developed. And by studying this system we designed system which is described in this paper This chapter deals with the brief description of various E Voting Systems published in IEEE papers by the IEEE Computer Society on E-voting.

\section{A. Three Ballot Based Secure Electronic Voting System}

The paper, “A Three-Ballot-Based Secure Electronic Voting System "written by Regivaldo G. Costa,Altair O. Santin, and Carlos A. Maziero proposes a voting system based on three ballots[3].Fig. 2 Overview of proposed architecture. The voter has to cast three votes on the three ballots and all the three votes will have a unique numeric identifier. On the three ballot papers all the candidates will be marked once randomly and the voter also marks the desired candidate. Thus the desired candidate has two marks and the remaining candidates will have only one mark. The voter then chooses one ballot randomly and then that is given as a vote receipt. Once the elections are done, the electoral authority publishes the vote receipts so that the voter can verify if their votes were counted. As per the proposed block diagram the voters first present themselves to the registration agent to get a credential that would enable them to cast their vote (event 1 in Figure 1) [3]. The registration agent then obtains ballot Ids (BIDs; event 2) and generates credentials that are returned to the voters. After authentication (event 3), voters cast their vote using a voting console (event 4). The vote is then stored in the electronic ballot box(event 5) and a vote receipt is issued(event 6).On the result day, counting phase(event 7) starts and the electoral authority publishes the vote receipts on the electronic election bulletin board(event 8)[3].

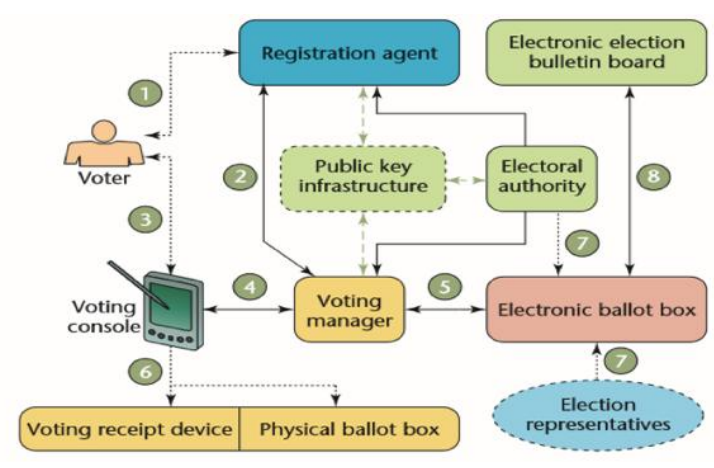

Fig. 2 Overview of proposed architecture 


\section{B. Direct Record Electronic (DRE) System \& Voter verified Paper Record System (VVPRS)}

A DRE voting machine with VVPRS capability includes a ballot display unit along with a voting panel. It also consists of internal and external memories. It includes a paper-record display unit, and a paper-record storage unit and a printer to print the paper record. Once the voters verify their vote casted, the EC officials couple the electronic version of vote with the paper record. Four differently manufactured machine types with different configurations were tested. All the machine types $1,2,3 \& 4$ had a 32 " $/ 15$ " LCD touch screen. All of them were primarily powered by an alternating current with additional battery backup of 16 hours for machine $1 \& 2$ and 2 hours for machine $3 \& 4$. The ballot was activated using RFID tags. The storage devices included built-in memory, flash drive, DVD for $\mathrm{m} / \mathrm{c} 1$; built-in memories, a proprietary device designed by Personal Computer Memory Card International Association (PCMCIA) for m/c 2; builtin memories, a proprietary PCMCIA device for $\mathrm{m} / \mathrm{c} 3$; three built in memories; a compact flash card; a proprietary, IrDA designed device for $\mathrm{m} / \mathrm{c} 4$. The paper record storage unit of VVPRS included a metal box for $\mathrm{m} / \mathrm{c} 1$; a bag for $\mathrm{m} / \mathrm{c}$ 2 and a spool for $\mathrm{m} / \mathrm{c} 3 \& 4$. Thermal printers were used and two methods were adopted: cut and drop VVPRS for $\mathrm{m} / \mathrm{c}$ $1 \& 2$ and a continuous spool for $\mathrm{m} / \mathrm{c} 3 \& 4$. The paper supply capacity extends up to 600 votes for $\mathrm{m} / \mathrm{c} 1 ; 500$ votes for $\mathrm{m} / \mathrm{c} 2$ and 120 votes for $\mathrm{m} / \mathrm{c} 3 \& 4$.

\section{Optical Scan E-Voting System, "DEMOTEK"}

Demotek is an electronic system that scans paper ballots using an optical character recognition (OCR). The OCR scanner of Demotek has two slots in which one is for reading and validation and the other for counting. The ballot resembles the traditional ballot papers but with a variation that it contains a special strip which consists of text that are visible only in the presence of UV light. The polling booths have UV Light systems. The voter covers the coting part by folding ballet paper. The Demotek then scans the UV readable part.

The voter's handover their ballot paper to the polling booth president who deposits them in the box through the second slot. Once all the ballot papers are deposited the polling booth president is in charge of locking the ballot boxes. The polling booth president uses an administrator card for the above purpose. On the election day, the administrator card is presented to the OCR system and the Demotek displays the final results. The Demotek prototype secures privacy by scanning UV readable labels that voters have checked [5]. Voters give their paper ballot to the polling place president, who then deposits the ballot into the box through the second slot [5]. Paper ballots will remain inside the transparent ballot box till the end of Election Day [5]. If someone wants to audit the results given by the e-voting system, the paper ballots are available for manual counting [5]. Once all votes are recorded and secured in the ballot box, the polling place president must close the electronic ballot box, using an administrator card designed for that purpose[5]. When he or she presents this card to the OCR system, it displays the final results and transmits them to the Central Electoral Office (where all the results of all the electronic ballot boxes are collected and counted) via GSM short messages.

\section{ANALYSIS TABLE}

\begin{tabular}{|c|c|c|c|}
\hline & 3 BALLOT SYSTEM & DEMOTEK & DRE-VVPRS \\
\hline USER INTERFACE & Voting console & Small display next to OCR Scanner on the lid & $\begin{array}{lll}32 " / 15 " & \text { LCD } & \text { Touch } \\
\text { Screen } & & \\
\end{array}$ \\
\hline $\begin{array}{l}\text { METHODS FOR } \\
\text { VOTER } \\
\text { AUTHENTICATION }\end{array}$ & Biometric devices & Manual authentication using voter's ID & RFID smart card \\
\hline $\begin{array}{l}\text { ASSISTENCE FOR } \\
\text { DISABLED ON VOTING } \\
\text { INTERFACE }\end{array}$ & $\begin{array}{l}\text { Braille code can be used on } \\
\text { the voting console }\end{array}$ & Absent & $\begin{array}{lll}\text { Audio } & \text { Assistance } & \text { is } \\
\text { present }\end{array}$ \\
\hline VOTE RECEIPT & $\begin{array}{l}\text { One ballot chosen at random } \\
\text { by the voter is copied as a } \\
\text { vote receipt }\end{array}$ & $\begin{array}{l}\text { After casting the vote, a code is generated for } \\
\text { each voter that's displayed on the monitor }\end{array}$ & $\begin{array}{l}\text { Printed voter verified } \\
\text { receipt is given to the } \\
\text { voter }\end{array}$ \\
\hline ACCURACY & $\begin{array}{l}\text { Possible problems due } \mathrm{o} \\
\text { system failures or attacks. }\end{array}$ & $\begin{array}{l}\text { Possible problems due o system failures or } \\
\text { attacks. }\end{array}$ & $\begin{array}{l}\text { Possible problems due } \mathrm{o} \\
\text { system failures or attacks. }\end{array}$ \\
\hline STRIKING FEATURES & $\begin{array}{l}\text { Security ensured through the } \\
\text { use of public and private } \\
\text { keys. }\end{array}$ & $\begin{array}{l}\text { Various means for data transmission are used. } \\
\text { If any one of the transmission for example } \\
\text { transmission through landline is intercepted, } \\
\text { then the data transmitted via Internet and cell } \\
\text { phone will reach agreement of two out of } \\
\text { three will take place thus boosting the } \\
\text { security. }\end{array}$ & $\begin{array}{l}\text { Use of printed voter } \\
\text { verified paper records } \\
\text { through which user can } \\
\text { check if his/her vote has } \\
\text { been counted. }\end{array}$ \\
\hline
\end{tabular}




\section{IV.BLOCK DIAGRAM}

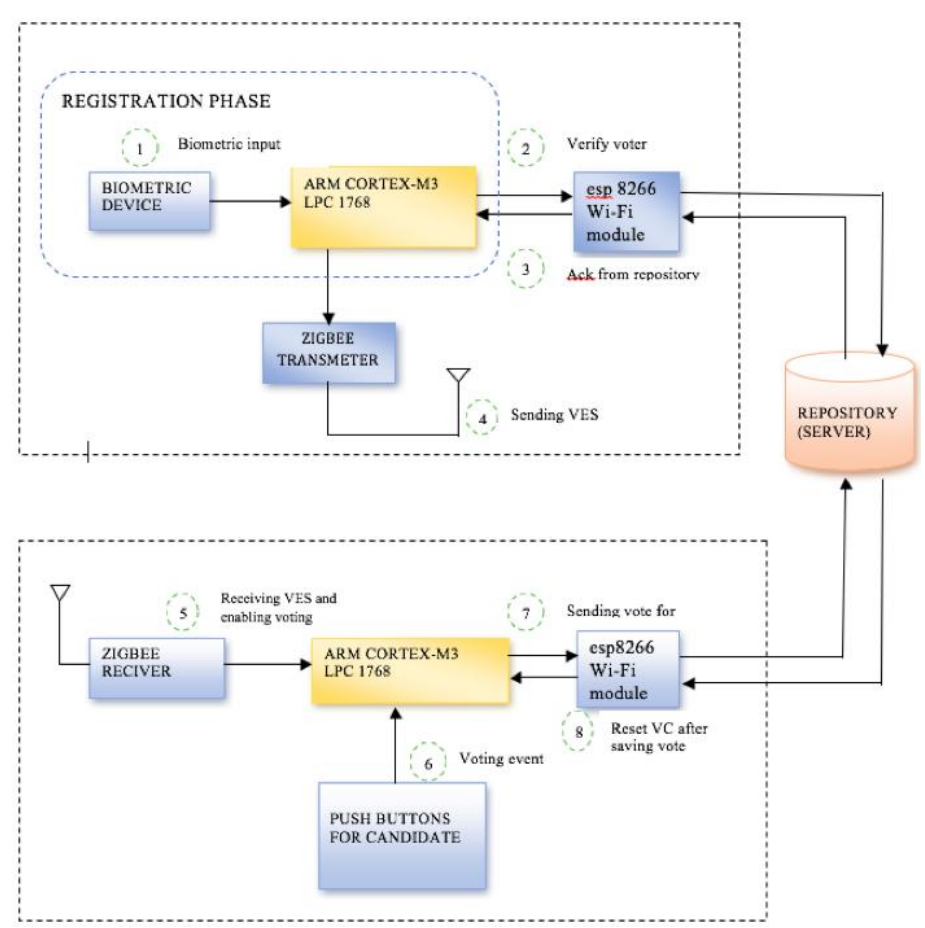

Fig. 3 Block Diagram of system

\section{SYSTEM OPERATION}

\section{A. VOTER VERIFICATION PHASE:}

The registration agent is responsible for voters admission and qualification during the registration phase. The registration agent comprises of a Biometric device (R305) and a processor (ARM Cortex M3 LPC 1768). The server will maintain two different repositories: Voter/ID repository: This database will have the list of eligible voters which will be accessed during the authentication process in the registration phase (i.e. to check if the voter is eligible to vote and once voter is approved his name will be cut). Vote repository: This database will consist of the various parties and their corresponding votes and will be accessed during the voting phase and the counting phase. As shown in the above figures, there are various events represented by E1 to E8. Once the registration phase starts, voters should identify themselves to the registration agent. In the event E1 the voter's fingerprint is obtained by Biometric device(BD). The event E2 represents the transmission of fingerprint input to the processor. The processor now communicates with the voter's repository (via esp8266). (refer event E3 in fig). The server then verifies whether the voter can vote by querying the database maintained by the Electoral authority and sending a positive acknowledgement signal if he is eligible to vote and a negative acknowledgement signal if not, to the processor (refer event E4). Event 5 represents the transmission of the enable signal from registration agent to the voting manager so that the voter can cast his vote to the voting manager.

\section{B. Voting}

The voting phase will consist of an Electronic voting machine comprised of various buttons against which the names of the respective parties along with their party symbols will be mentioned. The voter will cast his vote by pressing the button representing the desired party. The LED will blink ensuring the voter that his vote has been casted.

\section{Storage}

The vote will be transmitted wirelessly to the server and will be stored (refer event 7 in fig.). Once the vote has been stored successfully the server will send an acknowledgement signal to the Electronic Voting Machine which will reset the machine and then the voter may leave. Simultaneously the server will cut his name from the database consisting of eligible voters to prevent redundant voting malpractices.

\section{Counting Phase}

Only the election authorities will have access to the server. Once the elections have been conducted successfully the election authorities will access the vote repository to announce the result. 
International Journal of Advanced Research in Computer and Communication Engineering ISO 3297:2007 Certified

Vol. 6, Issue 4, April 2017

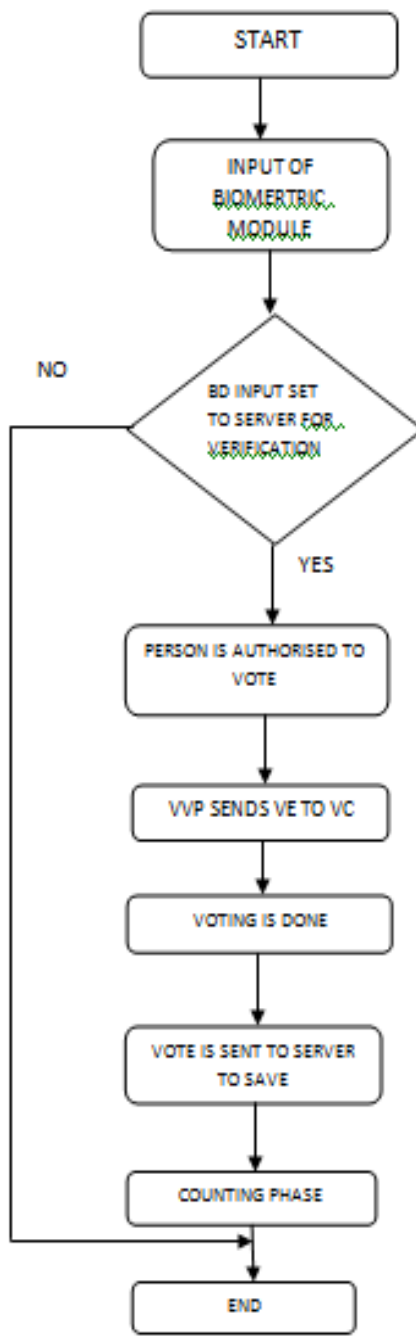

Fig. 4 Flowchart of working.

\section{RESULTS AND DISCUSSION}

The result of voting is stored on web server and it is displayed on website.

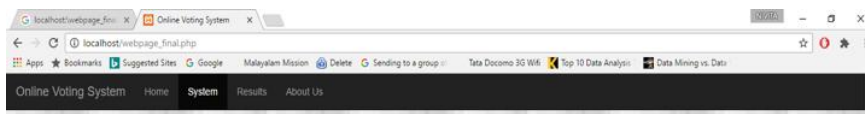

RESULTS

The Voting Results of this Elections

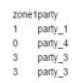

$=0$

Fig. 5 GUI for showing result after election 


\section{CONCLUSION}

This paper discusses the working principles of traditional EVM system and the various problems concerned with the existing system. In the later part of the paper an electronic voting system has been proposed which uses biometric authentication and the votes casted are stored on a central server. The key points served by this system are :

- Easy implementation

- Easy usage

- Use of a reliable wireless connection

- Keeps a check on Rigging and other malpractices

- Flexibility to vote from any polling booth.

\section{REFERENCE}

[1] D. Balzarotti, G. Banks, M. Cova, V. Felmetsger, R. A. Kemmerer, W.Robertson, F. Valeur, and G. Vigna, "An Experience in Testing theSecurity of Real-World Electronic Voting Systems",IEEETransactions on Software Engineering, vol. 36, no. 4, 2010.

[2] A. Villafiorita and K. Weldemariam, and R. Tiella, "Development,Formal Verification, and Evaluation of an E-Voting System withVVPAT," IEEE Transactions on Information Forensics and Security,vol. 4, no. 4, 2009

[3] Regivaldo G. Costa,Altair O. Santin, and Carlos A. Maziero "A Three-Ballot-Based Secure Electronic Voting System", IEEE Security \& Privacy, IEEE Computer Society.

[4] Nirwan Ansari, PitipatanaSakarindr, Ehsan Haghani, Chao Zhang, Aridaman K. Jain and Yun Q. Shi "Evaluating Electronic Voting Systems Equipped with Voter-Verified Paper Records", IEEE Security \& Privacy, IEEE Computer Society.

[5] IñakiGoirizelaia, MaiderHuarte, and JuanjoUnzilla and Ted Selker , "An Optical Scan E-Voting System based on N- Version Programming", IEEE Security \& Privacy, IEEE Computer Society.

[6] Ashok Kumar D., UmmalSariba Begum T., "A Novel design of Electronic Voting System Using Fingerprint", International Journal of Innovative Technology \& Creative Engineering (ISSN:2045-8711),Vol.1,No.1. pp: 12 19, January 2011.

[7] Benjamin B., Bederson, Bongshin Lee., Robert M. Sherman., Paul S., Herrnson, Richard G. Niemi., "Electronic Voting System Usability Issues", In Proceedings of the SIGCHI conference on Human factors in computing systems, 2003. 